\title{
Educação e trabalho no país da mais valia: a EPT no contexto do movimento do capital no Brasil
}

\author{
Education and work in the country of added value: the EPT in the context of the movement of \\ capital in Brazil \\ Educación y trabajo en un país de valor agregado: el EPT en el contexto del movimiento de \\ capitales en Brasil
}

Recebido: 03/08/2021 | Revisado: 07/08/2021 | Aceito: 10/08/2021 | Publicado: 14/08/2021

Orlando Bif

ORCID: https://orcid.org/0000-0001-6803-8492 Instituto Federal de Educação Ciência e Tecnologia de Santa Catarina, Brasil E-mail: orlando.bif@ifsc.edu.br Jair José Maldaner

ORCID: https://orcid.org/0000-0002-8288-6583 Instituto Federal de Educação, Ciência e Tecnologia do Tocantins, Brasil E-mail: jair@ifto.edu.br

Marcelo Rythowem

ORCID: https://orcid.org/0000-0001-5819-3800 Instituto Federal de Educação, Ciência e Tecnologia do Tocantins, Brasil E-mail: marcelo@ifto.edu.br

Roberta Pasqualli

ORCID: https://orcid.org/0000-0001-8293-033X Instituto Federal de Educação, Ciência e Tecnologia de Santa Catarina, Brasil E-mail: roberta.pasqualli@ifsc.edu.br

\begin{abstract}
Resumo
O ensaio teórico nomeado 'Educação e trabalho no país da mais valia: a EPT no contexto do movimento do capital no Brasil' tem como objetivo apresentar reflexões acerca das políticas públicas para Educação Profissional e Tecnológica (EPT) ao longo da história da educação profissional brasileira à luz da legislação brasileira e do olhar de pesquisadores como Rua (2014), Nosella (2011), Ortigara \& Ganzeli (2013), Saviani (1999), Martins (2018), entre outros. Do ponto de vista metodológico, essa pesquisa se classifica como sendo de natureza bibliográfica, de caráter descritivo e qualitativo. São abordadas questões de cunho histórico acerca da educação profissional com o objetivo de desvelar seus sujeitos, influências políticas nacionais e internacionais, lutas travadas e a travar. Destaca-se que é histórico o descaso das políticas públicas para os que vivem do trabalho na história da educação profissional, pois se privilegiou sempre a formação para as demandas que operadas pelo mercado de trabalho.
\end{abstract}

Palavras-chave: Educação profissional e tecnológica; Educação; Trabalho.

\begin{abstract}
The theoretical essay entitled 'Education and work in the country of added value: EPT in the context of the movement of capital in Brazil' aims to present reflections on public policies for Professional and Technological Education (EPT) throughout the history of Brazilian professional education in the light of Brazilian legislation and the view of researchers such as Rua (2014), Nosella (2011), Ortigara and Ganzeli (2013), Saviani (1999), Martins (2018), among others. From a methodological point of view, this research is classified as bibliographical, descriptive and qualitative in nature. Issues of a historical nature about professional education are addressed with the aim of revealing its subjects, national and international political influences, and struggles to be waged. It is noteworthy that the neglect of public policies for those who make a living from work in the history of professional education is historical, as training has always been privileged for the demands operated by the labor market.
\end{abstract}

Keywords: Professional and technological education; Education; Job.

\section{Resumen}

El ensayo teórico titulado 'Educación y trabajo en el país de valor agregado: EPT en el contexto del movimiento de capitales en Brasil' tiene como objetivo presentar reflexiones sobre las políticas públicas para la Educación Profesional y Tecnológica (EPT) a lo largo de la historia de la educación profesional brasileña en a la luz de la legislación brasileña y la visión de investigadores como Rua (2014), Nosella (2011), Ortigara y Ganzeli (2013), Saviani (1999), Martins (2018), entre otros. Desde el punto de vista metodológico, esta investigación se clasifica en 
carácter bibliográfico, descriptivo y cualitativo. Se abordan temas de carácter histórico sobre la formación profesional con el objetivo de dar a conocer sus temáticas, las influencias políticas nacionales e internacionales y las luchas por librar. Es de destacar que el descuido de las políticas públicas para quienes se ganan la vida con el trabajo en la historia de la educación profesional es histórico, pues la formación siempre ha sido privilegiada por las demandas operadas por el mercado laboral.

Palabras clave: Educación profesional y tecnológica; Educación; Trabajo.

Diante das experiências do mundo moderno, nós precisamos mirar o mais possível na preparação do aluno não somente para si mesmo, mas também para entrar na sociedade, se não com a capacidade de ser um produtor de cultura em todos os campos, pelo menos com a capacidade de desfrutar, isto é, de saber gozar de todas as contribuições da civilização humana, das artes, das técnicas, da literatura. (Manacorda, 2007).

Também se ensina através daquilo que se oculta. (Santomé, 1995).

Quanto mais restrito se torna o mercado de trabalho, menos distrações são toleradas por parte da educação. (Sacristán, 2013).

\section{Introdução: as Políticas Públicas - Para Que, Por Que e Para Quem?}

Ao iniciar esse ensaio teórico busca-se refletir acerca questões relativas às políticas. Nesta direção, compreende-se que uma política pública independe de uma decisão apenas. Rua (2014) enfatiza que as ações para implementação devem ser orientadas por estratégias selecionadas que objetivem as decisões tomadas para sua viabilização. O que caracteriza uma política é a decisão e ações que tem como proponente o poder público no uso pleno de sua autoridade e da atividade política que originam as políticas públicas. Simplificando, a autora considera que a quase a totalidade da atividade política do governo é destinada a tentar dar conta da diversidade de demandas que podem ser dirigidas tanto por atores sociais ou as que tem formulação nascente no próprios agentes do sistema político no momento em que articulam apoio para sustentar estas políticas.

Para Rua (2014) são basicamente três tipos de demandas cujos aspectos considerados devem levar em conta o seguinte: (a) demandas novas, surgidas com a emergência de novos atores políticos e/ou problemas inéditos; (b) demandas recorrentes: são caracterizadas por problemas que foram ou são resolvidos ou, quando resolvidos, não o foram de forma adequada e, por isso, estão amiúde na agenda governamental e, (c) demandas reprimidas: são demandas acumuladas e resultam da falta de vazão, diante de tal, as reivindicações acabam causando sobrecarga no sistema.

Rua (2014) escreve que a política é compreendida como um conjunto de procedimentos cujo objetivo é resolver os conflitos resultantes da disputa pela parcela recursos e/ou bens públicos dispostos pelo Estado. Os enfrentamentos, neste cenário, são entre a variedade de 'atores políticos'. Há uma série de atores políticos e, se há diversidade de atores, evidentemente, tornam-se diversas suas características.

A autora distingue os dois mais comuns: os públicos e os privados. Os primeiros mobilizam recursos e estão vinculados a esta função (políticos e burocratas). Os políticos são os que detém mandato logo, está em jogo a sobrevivência eleitoral dos mesmos e isso é levado em conta na ação com relação à alocação de recursos públicos.

Já os burocratas, dimensionam sua atividade a partir dos cargos - com conhecimentos especializado - que ocupam. Estão sob seu controle recursos de mando e controle das informações. Não é incomum haver conflito entres estes e os primeiros e, também, entre os próprios agentes da burocracia governamental. Basta acompanhar o noticiário nas mídias brasileiras para buscar evidências disto. O pragmatismo que caracteriza o grupo de congressistas que formam o 'centrão', por exemplo, tem embates com agentes do governo e mais, como agregam força para 'pedir a cabeça' de um Ministro ou membro de uma equipe econômica, por exemplo, explicita bem este tipo conflito. Acreditamos que aqui, cabe aqui a risível e elucidativa frase do cineasta Wood Allen: “A vocação do político de carreira é fazer de cada solução um problema.”. Em relação aos atores privados é saliente a desenvoltura dos empresários, tanto federados como individualmente. São atores que 
por sua relação direta com a atividade econômica tem forte influência em determinar, - a maioria das vezes por meio de loobies -, arranjos ou alteração nas políticas e no 'ânimo do mercado'.

Outro autor relevante neste cenário são os trabalhadores e sua organização de classe. Dependem, é claro, de como está estruturada está para conferir eficácia e força à sua atuação. Um exemplo são os bancários que possuíam muito mais força em determinado período histórico entretanto, na medida em que houve uma reestruturação do sistema financeiro e, ato contínuo, 'enxugamento' dos postos de trabalho pela recomposição das agências bancárias - que descartou milhares de trabalhadores substituídos pelo autoatendimento - arrefeceu a força desta categoria.

Junior (2007) assim resume este processo:

As modificações ocorridas no âmbito da produção deram-se através de intensificação de desenvolvimento científicos e tecnológicos aplicados a produção e de novos métodos de controle e gestão da força de trabalho - que viriam modificar o quadro das ocupações e dos empregos, assim como o conjunto da produção e do consumo. (Junior, 2007, p. 6).

Esta força pode ser medida lembrando que na década de 1980 uma greve de bancários não resistia a mais de uma semana pois, como paralisava o sistema, logo havia negociação. Atualmente as greves se arrastam por dias, pois os bancos continuam a disposição dos clientes pelos meios eletrônicos.

Agentes externos também entram no rol de atores importantes. Rua (2014) cita os representantes de bancos internacionais como o Fundo Monetário Internacional (FMI) e o Banco Mundial. Governos ou grupos que podem ter influência nos destinos das políticas e economia do país. Greenpeace e Anistia Internacional, em outra seara, também são exemplos destes agentes.

As conexões midiáticas entram no cômputo destes atores. No momento em que podem mobilizar multidões, seja levantando um problema ou mobilizando por uma campanha de 'interesse da sociedade'. É muito comum ver na TV, por exemplo, matérias sobre problemas encontrados por comunidades em relação ao descaso da prefeitura e/ou governo do estado. Mas, não só, basta lembrar a campanha feroz liderada pela Rede Globo contra o projeto de Agência Nacional do Cinema e do Audiovisual (ANCINAV) durante o governo Lula. Tanto que o projeto não prosperou, acusado de ter como objetivo a censura e o controle sobre a produção dos meios audiovisuais. Evidentemente que, com a ascensão da internet, a televisão e as mídias impressas não tem o alcance absoluto de antanho, mas ainda alcançam uma parte considerável da população, até porque aderiram às redes sociais.

Para Rua (2014) a identificação dos autores em relação às políticas públicas se faz usando um critério simples e eficaz: uma política que tem algo em jogo e quem ganha e quem perde com tal política e os interesses afetados por uma decisão nesta esfera. A autora define 'estado de coisas' como algo que é prejudicial e cria insatisfação, mas não chega a entrar na agenda governamental. A partir do momento em que esse 'estado de coisas' atrai a atenção e a preocupação de autoridades é que vem a se constituir com um 'problema político'; quando o 'estado de coisas' se perpetua seja por barreiras culturais e institucionais e não estimulam o debate público como, por exemplo, a descriminalização do aborto. Neste caso são conceituadas como "não decisão".

Para Rua (2014) o que vai elevar um 'estado de coisas' para o patamar de problemas políticos é o instante que mobiliza a ação política. Ao fazer essa travessia passa a ser incluída na agenda governamental e dá-se início à formulação de alternativas. Momento importante do processo decisório quando os atores apresentam suas 'cartas no jogo' e, por serem diversos, existe confronto entre os interesses. Mesmo assim pode acontecer, em alguns casos, de haver certa acomodação em relação aos interesses conflitantes para que, neste caso, um dos lados não alcance ganhos em sua totalidade e, nem do outro lado, perca na mesma proporção. Cada qual cede para que não haja escaramuças com custos incontornáveis. A acomodação 
pode tratar-se de uma estratégia com vistas ao fortalecimento da posição em outro contexto, quando a situação política e a correlação de forças favoreçam quem optou por essa estratégia.

As preferências estão incluídas no cálculo de custo/benefício relativa a cada um dos atores, elas fazem parte de uma das mais importantes etapas do processo que é 'formulação de alternativas', quando emerge às claras as preferências dos atores, pois cada qual possui o seu 'arsenal' que os torna mais ou menos forte no confronto. A preferência é a capacidade de criar soluções em benefício de um determinado ator.

Estas preferências dependem do cálculo de custo/benefício de cada ator. O cálculo de custo/benefício é o cálculo das vantagens e desvantagens que cada ator tem em relação a cada alternativa proposta para solucionar um problema. Este cálculo não se restringe a custos econômicos ou financeiros. Envolve também elementos simbólicos, como prestígio; ou elementos políticos, como ambições de poder e ganhos ou perdas eleitorais, por exemplo. (Rua, 2014, p. 7).

As preferências também são formadas através de issues ou custos. Rua $(2014$, p. 7) traduz issue como "item ou aspecto de uma decisão, que afeta os interesses de vários atores e que, por esse motivo, mobiliza as suas expectativas quanto aos resultados da política e catalisa o conflito entre os atores". Para demonstrar na prática como se configura um issue toma-se, como exemplo, a reforma agrária, pois dependendo da decisão tomada há perdas e ganhos entre os atores quando os interesses são afetados; pode mudar a configuração da política conforme a direção da decisão. Ao definir quais os issues de uma política é que podemos facilitar o entendimento do processo de formulação, uma vez que são identificadas as preferências dos atores relativas aos issues.

Rua (2014), ao destacar a dinâmica que envolve a relação entre atores em disputa, percebe três padrões, quais sejam: lutas, jogos e debates. A primeira acontece em um terreno onde tratam das políticas redistributivas e quando há um perdedor e um vencedor. A despeito de considerar a pior das situações em política, quando um tem que ganhar e outro perder, a autora ressalta que é possível acomodar os interesses em conflito, quando nenhum lado seja absoluto na vitória e nem outro saia da disputa de 'mãos abanando'. A autora sugere que este cenário pode ser uma estratégia de adiamento para um momento em que a conjuntura esteja favorável na correlação de forças. São os jogos de situação onde o que prevalece é a vitória sobre o adversário sem alijá-lo do processo, pois o que é adversário no presente pode se tornar aliado no futuro. É a negociação característica do mundo político, quando entram em cena as negociações, coalizões de interesses, etc.

Quanto aos 'debates' é a arte do convencimento que é característica desta estratégia. A proposta passa a ser aceita pelo ator convencido, sobressai o conhecimento técnico que é um recurso extraordinário. "A persuasão é a tentativa de buscar a adesão pela avaliação das possibilidades de um determinado curso de ação. Envolve análise e argumentação.” (Rua, 2014, p. $8)$.

Quando um problema entra na agenda governamental como prioridade é dado início ao processo de formulações de alternativas com as diferentes formas de encarar a solução para uma recepção de demanda chamado input. Além do modelo incremental a autora apresenta o modelo-racional-compreensivo e, também, uma terceira que é uma síntese das duas anteriores denominada, o mixed scanning.

O modelo incremental consiste na seleção de problemas passo a passo sem que haja mudança radicais nas situações presentes. A melhor decisão neste caso é aquela que assegura acordo satisfatório entre os interesses envolvidos. Constata-se, a partir disso a proeminência das relações de poder mesmo quando a fundamentação técnica atende a todas os requisitos necessários para a implementação da política. De modo que a solução política se sobrepõe a técnica e o contrário também é verdadeiro. Por isso a conclusão é que não existem soluções perfeitas. A autora constata que um governo democrático sempre vai encontrar limites quando se trata de destinação de recursos. 
No modelo racional-compreensivo a distinção vai além do alcance e proporção da distribuição dos recursos. A lógica que orienta a sua distribuição também deve ser levado em conta. O modelo racional-compreensivo permite que o conhecimento acerca do problema possibilite a tomada de decisão impactando em grande escala, neste caso, a tomada de decisão requer levantamento prévio de todas as informações sobre o assunto, estudo técnico, políticas que alcance a solução do problema. A decisão torna-se mais lenta. A questão central é realizar constantes mudanças.

Os dois modelos, no entanto, não estão imunes a problemas. O modelo incremental por ser mostrar minimamente compatível com as necessidades de mudanças e por seu caráter conservador. No modelo racional compreensivo os limites estão relacionados à falta de critérios para crença na perfeição da informação e por ignorar o peso da relação de poder quando da tomada de decisões. Ai que entra a concepção do modelo mixed scanning. Este exige dos tomadores de decisão engajamento quando a revisão do campo de decisão, não obstante sem detalhar cada alternativa como o faz o modelo racionalcompreensivo. Ao fazer esta revisão abre caminho para as decisões estruturadas. Ao contrário das incrementais que envolvem análises considerando os detalhes e alternativas especificas.

As demandas sugerem soluções de problemas e conta com as aspirações quanto a estas soluções. Aspirações dão lugar a expectativas quando as alternativas são formuladas conforme os autores na expectativa, positiva ou negativa, de acordo com o cenário e, em função destas expectativas que há mobilização dos autores. Quanto aos padrões eles são definidos de acordo com as características das políticas; se são redistributivas o padrão tende a ser pluralista. No caso de políticas regulatórias o padrão pode ser pluralista com tendência a ser elitista, a definição disso é a partir do problema a ser regulamentado.

No pluralismo, a princípio, todos os atores se equivalem, de modo que todos tem chance de ser apreciado por uma decisão, evidente que isso depende da capacidade de articulação de cada qual na disputa. A partir da disposição para o enfrentamento da disputa. No elitismo, ao contrário, o resultado e previamente definido pelas elites ou classes que controlam os recursos sociais, sejam eles econômicos ou organizacionais.

Há, em muitos, cenários uma disputa fratricida entre estes, o que pode ser aproveitado pelas classes que não se somam a estas, mas que, taticamente, podem ser aliados em uma disputa eventual.

Quanto à implementação Rua (2014) entende que esta pode ser compreendida como um conjunto de ações dos quais participam variados grupos, seja de natureza pública ou privada, que visam buscar objetivos a partir decisões prévias em relação às políticas. Estas ações são no sentido de viabilizar as políticas além do descrito no planejamento. Para a autora este processo precisa de um acompanhamento sistemático em todas as etapas para ser possível identificar porque várias são exitosas enquanto outros tantas 'naufragam' entre o momento da formulação e a confecção.

A autora coloca que é mais difícil haver um controle efetivo quando esta política enfoque várias esferas governamentais, diferentes regiões de um país ou setor de atividades, pois a implementação pode gerar muitos problemas uma vez que o controle é dificultado por este envolvimento. Até em nível local pode haver problemas se não há vínculos efetivos entre as várias organizações e agências públicas envolvidas que conduzam ao sucesso da implementação.

O acompanhamento e o controle das políticas não existe sem a inclusão do tipo de políticas e da arena onde se desenrola esta política. Os dois contextos devem ser levados em conta. Por um lado o contexto inter e intraorganizacionais onde ocorre a implementação e, por outro, a realidade apresentada pelo mundo externo e que será atingida por estas políticas. Soma-se a isso que os implementadores nem sempre são os sujeitos que estão situados na posição de direção política e, muitas vezes, desconhecem mesmo atuando na implementação de uma política abstratamente, a dimensão do trabalho em sua implementação. Além disso, há uma confusão entre o processo de formulação e de implementação de maneira que, são ignorados os objetivos e problemas com antecipação e, só são percebidos à medida que avançam as etapas de sua implementação. 
Frequentemente o estudo e o acompanhamento da implementação enfrentam a dificuldade de identificar o que é que efetivamente está sendo implementado, porque as políticas públicas são fenômenos complexos. Eventualmente, esta complexidade é deliberada, ou seja, em certos casos, as políticas formuladas podem ter apenas o objetivo de permitir que os políticos ofereçam ao público satisfações simbólicas, sem que haja nenhuma intenção verdadeira de implementá-las. (Rua, 2014, p. 17).

Por fim, Rua (2014) chama atenção para a dificuldade e os problemas resultantes de todo o processo que gira em torno das ações que se fazem políticas. Estas devem considerar que a implementação é um processo longo e inacabado, pois há um contínuo movimento que interage entre uma política em constante mudança, uma estrutura formada por relações de alta complexidade e o mundo exterior que, além de complexo, é caracterizado por mudanças que acompanham a velocidade de rotação do planeta.

Apresentada essa introdução à temática das políticas, seus atores e seus meandros, considerando que o objetivo deste texto é apresentar reflexões acerca das políticas públicas para Educação Profissional e Tecnológica (EPT) ao longo da história da educação profissional brasileira à luz da legislação brasileira e do olhar de pesquisadores, na sequência, apresenta-se a opção metodológica para materializar o ensaio aqui apresentado.

\section{Metodologia}

Para Silva e Pasqualli (2020, p. 4), “a metodologia de um estudo puramente teórico não pode fugir de um caminho que é exclusivo, isto é, o da pesquisa bibliográfica" e é nesta direção metodológica que este texto se constituiu.

É importante salientar também que a metodologia utilizada neste ensaio não seguiu um caminho puramente instrumental, pois o papel metodológico não se contenta com simplesmente recolher informações e analisá-las, isto é, não entende o método como uma lista de processos a seguir de acordo com uma receita pré-determinada. (Silva \& Pasqualli, 2020, p. 4).

Considera-se, assim como Franco (1999), que a metodologia é uma organização mais ampla da pesquisa, que engloba tanto os critérios de rigor científico, quanto à criticidade do pensamento reflexivo ou, como afirma o mesmo autor afirma "[...] para a verdadeira apreensão do real é preciso que o pensamento trabalhe o observável e vá além dele, concretizando-o por meio da consciência que é ativa, não por um dom sobrenatural, mas porque abstrai e apreende o movimento existente na totalidade.”. (Franco, 1999, p. 211).

Dito isto, considerando o caráter descritivo e qualitativo da pesquisa pode-se afirmar que a pesquisa se compromete com com a dialética da apreensão do real, focada nas relações entre o sujeito e o objeto que movimentam-se em determinações mútuas e produzem não somente o real, mas perspectivas sobre a realidade.

Acerca disto, (Silva \& Pasqualli, 2020, p. 5), destacam:

Tais perspectivas emergem das mais variadas maneiras e, inclusive, de forma contraditória. Portanto, é a tensão epistemológica proposta pelo método dialético que guiará guiou esta produção científica, visto que somente ele pode captar as contradições e os vários matizes de uma construção curricular coletiva. (Silva \& Pasqualli, 2020, p. 5).

Na sequência do ensaio, apresentam-se reflexões acerca dos caminhos políticos traçados para a educação profissional a partir de 1909.

\section{1909 Ecoa Entre Nós}

Ao fazer a introdução deste texto com as contribuições de Rua (2014), passamos a compor o texto com um histórico das políticas para EPT. Neste trajeto, foi possível perceber como se manifestam os vários atores que construíram esta história 
centenária e, como os vários atores descritos de maneira intemporal por Rua (2014) entraram em cena em diferentes períodos da história de formatação da EPT.

Há muito se fala da falta de mão de obra qualificada no Brasil. Fala-se que o país não conseguiria se desenvolver devido à qualificação dos trabalhadores estar a distância do ritmo de desenvolvimento a que chegamos. Que não temos no país escolas voltadas para a formação e capacitação da mão de obra preparada para alavancar o crescimento. Que esta ausência não consegue colocar o país no patamar das grandes nações no ritmo do desenvolvimento industrial para dar conta das exigências do processo de globalização em que o mundo está inserido. Sobre isto, pedimos atenção ao seguinte trecho de editorial em um grande jornal de circulação nacional constata-se esta apologia ao ensino profissional:

Mão-de-obra-difícil: A recente aprovação, no Senado, da Rede Federal de Educação Profissional, Científica e Tecnológica é um passo pequeno, ainda que na direção correta, para preencher uma das grandes lacunas na formação dos brasileiros: o ensino profissional. (...). Para ser bem sucedida, é importante que essa expansão contemple principalmente os alunos do ensino médio. (Folha de S. Paulo Editorial, 28 dez. 2008 apud Nosella, 2011).

Muitos reivindicam o papel preponderante da educação para preencher esta lacuna. Amiúde se ouve falar que o problema de fundo do país reside na falta de educação ou, que a falência da educação nos torna atrasados em relação ao resto do mundo. Mas de qual educação estamos falando? E o quando se fala de educação profissional em que fundamentos epistemológicos estaria assentada?

Para Ortigara e Ganzeli (2013), a trajetória da educação profissional no Brasil é marcada pela dualidade entre a unilateralidade da formação técnica que tem no mercado o seu fim e o ideário da formação que, além desta preparação, procura formar sujeitos autônomos que estejam preocupados com uma formação integral que leve em conta elementos que estão além da preparação para uma colocação no mercado do trabalho. Para tentar explicar esta dualidade, os autores destacam a reforma no ensino brasileiro nos anos 1990 , tendo como referência a publicação do Decreto $\mathrm{n}^{\circ}$ 2.208/97, quando foi promovida a separação completa entre o ensino médio propedêutico e a educação profissional e, nos anos 2000, as reformas a partir da publicação do Decreto $n^{\circ}$ 5.154/2004 durante o primeiro mandato na gestão federal pelo Partido dos Trabalhadores. Silva, Pasqualli, Greggio e Agne (2016) destacam que, a partir de 2004, ao reunir em uma mesma instituição diferentes unidades de ensino, exigiu-se o desafio para a formação integral dos estudantes na medida em que acumulou educação propedêutica, profissional e ensino superior o que indicou uma inovação na estrutura para formação à cidadania.

Nesta direção, vamos voltar uma centena de anos no tempo até o ano 1909 quando se criou um conjunto de escolas de aprendizes artífices para instrumentalizar a 'classe operária' desejosa de emprego na incipiente indústria nacional. Prover os 'desfavorecidos da fortuna' foi a expressão usada no Decreto $n^{0}$ 7.565/1909 com a assinatura do presidente Nilo Peçanha, quando do ato de criação dessa modalidade de escola. Em cada capital de estado foi construída uma escola e "nesse sentido, não há dúvida de que os objetivos da escola de aprendizes artífices se associavam a qualificação da mão de obra e o controle social de um segmento especial: os filhos da classes proletárias, jovens em situação de risco social”. (Instituto Federal de Educação, Ciência e Tecnologia Catarinense, 2009, p. 2).

Destarte, já em seu embrião, as primeiras instituições desta rede estavam vinculadas a formação para o mercado de trabalho e a proteção de crianças em situação de vulnerabilidade, para usar um termo recorrente atualmente. $\mathrm{O}$ que se observa desde então é que as escolas de formação propedêutica eram o destino dos filhos pertencentes à classe dominante, enquanto que as crianças da família pobres destinavam-se a formação restrita ao aprendizado de uma especialidade que constituía segundo entendem e, nesta direção destaca-se que "a dualidade é antiga e perdura até hoje, só não esteve presente no ensino médio antes do processo de industrialização, pois os jovens destinados aos trabalho não tinham direito a escola.”. (Nosella, 2011, p. 1054). 
Com a transição do modelo agrário para modelo industrial, baseado no crescimento das cidades e na ascensão da classe urbano industrial, que viria apoiar o movimento que deslocou Getúlio Vargas do governo da província do Rio Grande do Sul para a capital federal nos anos 1930 foi criado o Ministério dos Negócios, da Educação e Saúde Pública, fruto das disputas que ocorriam quanto ao modelo de desenvolvimento do país e que afetaram também o modelo institucional para a educação profissional. Ao ensino técnico industrial restou estar sobre a responsabilidade do Ministério em questão, que foi resultado da cisão nos órgãos de gestão de políticas para educação profissional. De um lado, o ensino com estas características representava correntes do modelo urbano industrial baseado na industrialização e, no outro extremo desta disputa, o ensino agrícola que continuaria atrelado à gestão do Ministério dos Negócios da Agricultura, Indústria e Comércio onde eram atendidas as demandas dos setores que faziam a defesa do modelo de desenvolvimento que tinha como base a produção agrícola.

Em 1937, as escolas de aprendizes e artífices deram lugar aos liceus destinados a oferecer ensino profissional em todos as graduações e diversos ramos. Já em 1940 foi a vez dos liceus serem extintos e deles resultarem, por meio da lei orgânica do ensino industrial oferecerem a formação profissional em nível secundário por meio do Decreto-Lei nº 4.073/1942. O ensino industrial passa a ser articulado ao ensino propedêutico. No período que compreende os anos 1930 a 1945 quando politicamente vigorava o Estado Novo e a economia agroexportadora perdeu espaço para a crescente indústria, apoiada pelo Estado, abriu-se espaço para criação das escolas profissionalizantes.

Já o ensino agrícola é tratado na lei orgânica homônima instituída pelo Decreto $n^{\circ}$ 9.613/1946 que dividiu os estabelecimentos de ensino deste ramo adotando a seguinte classificação: escolas de iniciação agrícola, escolas agrícolas e escolas agrotécnicas. As escolas industriais e técnicas foram transformadas em autarquias federais em 1959 com a designação de escolas técnicas federais.

Com a aprovação da primeira Lei de Diretrizes e Bases da Educação (LDB), em 1961, por meio dada publicação da Lei $\mathrm{n}^{\circ}$ 4.024/61 ficou estabelecido que todas as instituições de ensino estariam subordinadas ao MEC. Além disso, a LDB estabeleceu a equivalência entre cursos técnicos e propedêuticos em atendimento as reivindicações dos que propugnavam um escola unitária, de qualidade e universal. Segundo Santos apud Ortigara e Ganzeli (2013) a equivalência legal não seria suficiente para superar a dualidade existente entre as duas formações, "tendo em vista a permanência de duas redes de ensino no sistema educacional brasileiro, de modo que o ensino secundário continuou mantendo o maior reconhecimento social" (Ortigara \& Ganzeli, 2013, p. 260).

Com o advento do golpe de estado em 1964 foi instituída, em 1971, a Lei Federal no 5.692/71 substituindo a equivalência entre os ramos secundários e propedêutico tornando compulsória a habilitação profissional para aqueles que cursassem o que viria a ser chamado de ensino do segundo grau, em tese estava-se sugerindo o fim da dualidade entre os dois ramos de ensino, em termos práticos a implementação de tal política se deu distintivamente conforme os estabelecimentos de ensino. Com esta distinção bem marcada entre escolas da rede pública e privada.

No âmbito federal, as Escolas Industriais e Agrícolas formavam o segmento com mais disponibilidade de recursos, tanto para contratação de professores como para instalação de laboratórios; seus currículos foram reestruturados e, dispondo de tempo integral, foram neles acomodadas a formação geral e a formação profissional, consolidando, assim, a sua atuação no setor industrial e no setor agropecuário, respectivamente." (Ortigara \& Ganzeli, 2013, p. 261).

Os primeiros CEFETs nasceram em 1978 e, com eles, a ampliação de ingressos, pois passaram a ofertar ensino superior, formando engenheiros e tecnólogos a partir de três escolas situadas no Paraná, Minas Gerais e Rio de Janeiro que até então eram denominadas Escolas Técnicas Federais. Um ano após, tanto as escolas agrícolas com as industriais, passaram a atender pela denominação de Escolas Técnicas Federais e Escolas Agrícolas Federais, respectivamente. 
Na sequência deste ensaio, apresenta-se o cenário da educação profissional a partir da promulgação da Constituição de 1988.

\section{4. "Um Novo Tempo, Apesar dos Perigos"}

Com a promulgação da Constituição de 1988, resultado do processo de redemocratização após anos de repressão e restrições às liberdades, as discussões acerca das relações entre o ensino propedêutico e o profissional foram incorporadas nas pautas de discussões educacionais nacionais, especialmente pela atuação de representantes do setor da educação também oriundos do 'Fórum em Defesa da Educação' formado com vistas a garantir espaço na agenda pública de acesso à educação para todos os brasileiros. (Pasqualli, Silva \& Silva, 2019a);

Discussões e propostas com o fim de aprovar uma nova LDB surgiram e, segundo Saviani (2004), o projeto de LDB avançara enquanto diminuíra a dualidade entre as formas de ensino aqui discutidas, de modo que propugnava uma educação política que abrangesse a totalidade dos estudantes do ensino médio e a formação técnico profissional e como modalidade específica dos que fossem ao encontro da educação profissional.

Este processo foi atropelado pelo governo Fernando Henrique Cardoso (FHC) quando foi apresentada uma proposta feita, pelo então senador Darcy Ribeiro, de um substitutivo e da apresentação do Projeto de Lei no 1.603/1996 pelo MEC. Os dois projetos tinham como fundamento o mesmo discurso que demanda a educação para o trabalho levando em conta os cenários de globalização da economia e das mudanças em se tratando das novas tecnologias que foram incorporados ao processos industriais. Tal Projeto de Lei pretendia separar o ensino regular do profissional. Para Ortigara e Ganzeli (2013) isso "evidencia a intenção dos legisladores de não reconhecer o ensino regular como sendo fundamental importância para a formação do trabalhador". (Ortigara \& Ganzeli, 2013, p. 263).

A proposição do projeto em questão apontava para a ampliação da formação destinada a atender as necessidades do mercado de trabalho dando ênfase a educação profissional como alternativa à educação básica. Já o projeto do Senador Darcy Ribeiro a concepção de EPT não tinha vinculação com a educação regular. Assim sendo o ensino médio era visto com a última etapa da educação básica objetivando a formação que permitisse tanto o ingresso no mercado do trabalho e o acesso ao nível superior.

Cabe o destaque ao que Marx (1983) escreveu sobre o trabalho e, no qual, apoiamos nossos princípios:

[...] o trabalho é um processo entre o homem e a natureza, um processo em que o homem, por sua própria ação, medeia, regula e controla seu metabolismo com a natureza. Ele mesmo se defronta com a matéria natural como uma força natural. Ele põe em movimento as forças naturais pertencentes à sua corporeidade, braços, pernas, cabeça e mãos, a fim de se apropriar da matéria natural numa forma útil à própria vida. Ao atuar, por meio desse movimento, sobre a natureza externa a ele e, ao modificá-la, ele modifica, ao mesmo tempo, sua própria natureza. (Marx, 1983, p. 149).

A nova LDB acabou sendo aprovada, não obstante, usando pioneiramente a expressão 'educação profissional', mas não deixou de exprimir a dualidade entre as formas de ensino ao tratá-la com distinção esta modalidade de ensino. O governo FHC abandonou o Projeto de Lei 1.603/1996 para editar o Decreto n ${ }^{\circ}$ 2.208/1997, decretando a separação entre o ensino médio propedêutico de educação profissional, assim sendo, ficou estabelecido a independência entre um e outro.

A articulação entre as duas modalidades de ensino sobreviveu apenas na relação encontrada na forma concomitante e subsequente, para mais, o referido decreto alterou a organização curricular de forma que a formação profissional quando as disciplinas eram agrupadas por módulos que abriam possibilidade para formação intermediária, momento em que se acelerava a saída dos profissionais com qualificação a partir do que demandava o mercado de trabalho. 
Ortigara e Ganzeli (2013) observam que o contexto foi favorável a desvinculação do ensino médio da educação profissional acentuando, isso posto, a dicotomia entre as modalidades de educação.

A portaria MEC 646/1997 publicada pelo mesmo governo reduziu a oferta de ensino médio na rede federal uma vez que limitou a oferta por essa rede de maneira que tornou as escolas impossibilitadas de oferecer além de 50\% das vagas que dispunham para esta modalidade, o que forçava a oferta de exclusividade no curso profissionalizantes, ademais, as novas instituições estavam proibidas de oferecer ensino propedêutico (Ortigara \& Ganzeli, 2013).

Em 1997 o governo lançou o Programa de Expansão da Educação Profissional que era propalado com o objetivo de modernizar a expansão do sistema nacional de educação tecnológica com recursos distribuídos para escolas da rede federal, estadual e comunitária. Os recursos, embora públicos, foram carreados em sua maioria para as demandas do setor comunitário que, até o final de 2002, foram contemplados com 135 projetos enquanto ao setor federal alcançou $65 \%$. Sendo que na rede federal os projetos financiados atendiam apenas à reformas e equipamentos.

O segmento comunitário, vale dizer, representava a versão para educação das 'organizações sociais' propostas por Bresser Pereira na reforma do Estado. As escolas deste segmento receberiam recursos públicos para investimentos por meio de entidades sem fins lucrativos às quais passariam a ser responsáveis pela sua gestão. (Ortigara \& Ganzeli, 2013, p. 265).

Os autores entendem que ficou evidenciado neste modelo de gestão a 'mão invisível' do banco mundial com sua proposição de políticas não onerosas para o setor social. Esta política educacional como fator de desenvolvimento econômico inspirou reformas no sistema educativo com ênfase nos ganhos de capital com foco na formação de mão de obra. Enquanto o Estado reduzia suas atribuições em favor do modelo gerencial dos agentes como do setor comunitário para garantir atendimento educacional visando à formação profissional.

Sintetizando o período do governo FHC os autores afirmam que além de não favorecer a expansão da rede federal as escolas deste setor foram induzidas a fazer a adaptação de sua organização político-pedagógica, ato continuo, introduzir módulos e cursos de aprendizagem aligeirada, perspectivando a formação instrumental, e, em decorrência, potencializou a dualidade educacional. Formação técnica, sim, mas com ampliação dos horizontes do educando.

\section{O Universo da Rede Federal em Expansão}

Em 2002, no programa do então candidato à presidência Luiz Inácio Lula da Silva, anunciava-se que a orientação da política na área de educação seguiria uma linha que considerava a educação gratuita, unitária e laica no que tangia à esfera pública, além disso, a educação deveria contemplar a formação integral humanista. A proposta tinha como escopo superar a concepção vigente de um educação fragmentada buscando uma educação politécnica integral.

Pasqualli et al. (2019b), destacam que:

Com a eleição do ex-presidente Luiz Inácio Lula da Silva, amparada por um momento econômico positivo, a educação profissional brasileira passou por mudanças significativas. Após muitos debates e críticas da comunidade acadêmica ao Decreto $\mathrm{n}^{\circ} 2.208 / 1997$, o mesmo foi revogado e, em seu lugar, passou a vigorar o Decreto $\mathrm{n}^{\circ}$ 5.154/2004 que retomou e difundiu a articulação, de forma integrada, entre conhecimento específico e conhecimento técnico. (Pasqualli et. al, 2019b, p. 510).

Observa-se que a expressão unitária é a mesma utilizada por Gramsci a partir do qual se desenvolveu o conceito de escola integral. Nessa concepção, a instituição deveria ser unitária, e os processos de formação ocorreriam segunda a perspectiva da cultura geral, com a proposta de inserir os jovens na atividade social, humanística e formativa em que se equilibrasse a capacidade de trabalho manual e instrumental com o desenvolvimento das capacidades de trabalho intelectual. (Ferreti, 2009). 
A escola unitária de Gramsci adaptada para os dias de hoje depõe contra a dualidade da formação geral e profissional preponderante no ensino básico no Brasil. O conceito avança no sentido da superação de uma educação instrumental tão somente para os desígnios da indústria.

Se a ampla coalizão que tornou possível a eleição do candidato do Partido do Trabalhadores aproximou do governo forças conservadoras, também o fez com forças progressistas, através vários representantes da sociedade civil que estiveram alijados das discussões de políticas públicas - a despeito de encaminharem muitos projetos - com propostas de reformas estruturais durante o período do governo anterior. Muitas dessas discussões forjadas durante o processo constituinte nos anos 1980.

Essas discussões, principalmente, as que contemplam a EPT tiveram como resultado prático a revogação do Decreto $n^{\circ}$ 2.208/1997 substituído pelo Decreto $n^{\circ} 5.154 / 2004$ que, por sua vez, deu origem a Lei $n^{\circ} 11.741 / 2008$. A novidade prevista na lei foi a modalidade integrada de ensino como forma de articulação entre as duas formações para os que concluíssem o ensino fundamental. As modalidades concomitante e subsequente permaneceram como previstas no Decreto nº 2.208/1997.

Para Ortigara e Ganzeli (2013),

E importante assinalar que a possibilidade de integração do ensino médio com o ensino técnico representou um avanço no processo de redução da dualidade entre essas modalidades de educação. No entanto, o Decreto ${ }^{\circ}$ 5.154/2004 manteve as possibilidades de segmentação, como a organização dos currículos em módulos com saídas intermediárias, que possibilita a obtenção de certificados de qualificação para o trabalho, sendo isso uma característica da educação profissional voltadas aos interesses da forma capitalista de produção. (Ortigar \& Ganzeli, 2013, p. 269).

Em 2007 foi lançada pelo Governo Federal o Plano de Desenvolvimento da Educação (PDE). Entre as ações que o plano tratava havia a proposta de reorganização das instituições federais. Cabe lembrar que em 2006 na Conferência Nacional de EPT com ampla participação do setor da área de educação apresentara propostas de descentralização e expansão geográfica e interiorização.

O modelo proposto foi o que hoje conhecemos como Instituto Federais. A Lei $n^{\circ} 11.892 / 2008$ consolidou este processo e desta lei surgiu a Rede Federal de Profissional e Tecnológica criando os Institutos Federais de Educação, Ciência e Tecnologia. Dois anos depois já tínhamos 252 estabelecimentos de federais de ensino.

Entre 2005 e 2010 os estabelecimentos de EPT no Brasil haviam aumentado 20,24\% incrementado, principalmente, a rede de escolas públicas. Em nível estadual escolas que ofertavam educação profissional o aumento bateu os 67,56\%. (Ortigara \& Ganzeli, 2013).

Segundo informaç̃oes do Ministério da Educação e Cultura (MEC) não houve outro período da história que se comparasse àquele momento em termos de expansão do ensino técnico. Desde o início da educação profissional que completou 100 anos em 2009 foram criadas mais de uma centena de escolas técnicas no país. O plano de expansão da rede federal entregou, em oito anos, 214 escolas que foram previstas pelo plano de expansão da rede federal. Além deste conjunto de escolas muitas outras foram federalizadas.

A expansão da Rede Federal de EPCT foi vista com muito otimismo no âmbito educacional brasileiro, como podemos perceber nas palavras de Eliezer Pacheco:A Rede Federal, por sua excelência e seus vínculos com a sociedade produtiva, tem condições de protagonizar um projeto político-pedagógico inovador, progressista e que busque a construção de novos sujeitos históricos, aptos a se inserir no mundo do trabalho, compreendendo-o e transformando-o na direção de um novo mundo possível, capazes de superar a barbárie neoliberal e restabelecer o ideal da modernidade de liberdade, igualdade e fraternidade, sob a ótica das novas possibilidades abertas à humanidade neste princípio de século. (Pacheco, 2011, p.17). 
Quem de boa memória vai lembrar que, durante o período eleitoral para o primeiro mandato, a então candidata Dilma Roussef, propalava em seu programa de TV no horário eleitoral gratuito que sua meta era que em cada cidade de 50.000 habitantes seria construída uma unidade de escola técnica federal.

Segundo os autores, geograficamente, assim como em 1909 o plano de expansão neste período dos anos 2000 seguiu o mesmo princípio do início do século XX uma vez que procurou atender todos estados da federação onde não havia institutos com este perfil. A previsão da continuidade da expansão objetivava a construção de unidades em todas as cidades polos de desenvolvimento regional.

Assim, entendemos que os IFs pela sua abrangência geográfica, significam uma tendência de mudança no curso das funções do Estado, seguindo em sentido contrário às políticas restritivas de recursos públicos para educação profissional que vigoraram no governo FHC. As novas instituições, afinal, assumiram a função de instrumentos do Estado para a implantação de uma política pública, nesse caso a política para a educação profissional. (Ortigara \& Ganzeli, 2013, p. 274).

Para Maldaner (2016) as políticas para a EPT implementadas durante maior parte do governo Lula tem o distintivo teórico das concepções de Marx e Gramsci, a partir dos conceitos de politecnia e omnilateralidade e são integrantes da relação entre o trabalho e educação e, por isso, destinam-se à força de trabalho. Depois disso mais exatamente a partir de 2009, não obstante tivessem a direção da classe que vive do trabalho, perdeu a substância adquiridas pelas concepções que acabamos de citar e se voltaram ao pragmatismo de mercado de trabalho. Grosso modo, podemos dizer que o trabalho como princípio educativo foi substituído pelo princípios do mercado de trabalho.

O trabalho como princípio educativo é resultado do processo de industrialização. Quando homens e mulheres deramse conta que o conhecimento do qual necessitava a indústria resultava da articulação do par teoria e prática, já que o cérebro e as mãos, concomitantemente, operacionalizavam 'segundo as regras objetivas teóricas e práticas'. Por meio da experiência com a ciência, surge um novo método de produção a partir da forma como homem e natureza interagem.

Assim, o trabalho como princípio educativo passou a significar o objetivo geral de todo o processo educativo, isto é, capacitar às gerações mais novas a transformar a natureza, de forma cientifica, humanizando-a. Desta à instituição escolar competia desenvolver atividades didáticas próprias de cada fase etária (o trabalho como princípio pedagógico), visando alcançar o objetivo geral. (Nosella, 2011, p. 1058).

Para Martins (2018) foi a partir de 1996, com a nova LDB, que a atenção voltou-se para a formação geral do educando sem que incorresse em prejuízo da sua profissionalização. Para o autor, existe atualmente - pelo menos antes da Lei $\mathrm{n}^{\mathrm{o}} 3.415 / 2017$ - um esforço da teoria pedagógica que vai de encontro a relação do ensino-aprendizagem que reduz ao tecnicismo que não da margem para manifestações além do 'estímulos bem calculados' O significado do processo de aprendizagem "exige a descoberta de novos sentidos, com outras experiências de linguagem (Martins, 2018, p.133) e um processo educativo que recupere a dimensão educativa que, enquanto processo resultante do trabalho, tem que superar esta sociedade que cria mecanismos cada vez mais mantenedores de uma ordem que não leva em conta o ser humano enquanto sujeito que integra o mundo na sua totalidade.

A história da educação profissional no Brasil está inserida em um conjunto de lutas que muitos educadores e tantos outros atores buscaram e continuam perseguindo em prol de uma educação que não seja estranha aos detentores da força que produz a riqueza deste país. Bem verdade que os acontecimentos na esfera política mundial, com reflexo em nosso país, afastam tanto mais esta possibilidade de oferecer uma educação, publica, gratuita e com a qualidade desejada pelos que empunharam a bandeira de uma educação politécnica e omnilateral mas, a despeito de tudo, nunca é demais lembra a estimulante frase do autor dos 'cadernos: Pessimismo da razão, otimismo da vontade. 


\section{Algumas Considerações Finais}

A história da educação profissional no Brasil não pode ser distinguida dos processos sociais e das transformações pelo que passaram e passam a sociedade Brasileira.

Não há como separar as políticas públicas como uma coisa estanque da realidade, pois ela, como ensina Rua (2014) é feita construída ou não por diversos atores com distintos interesses e que ao longo dos anos tem disputado parcela do orçamento do Estado num jogo de perdas e ganhos.

Considera-se que os autores utilizados para a escrita deste ensaio são unânimes em afirmar que a educação tem de atuar numa dimensão que dê conta da formação do ser humano na sua totalidade e não uma educação voltada apenas para uma especificidade que retire do indivíduo sua capacidade de articular as várias formulações do pensamento.

Analisando as condições das classes trabalhadoras atualmente e como o sistema capitalista em seu novo ciclo de expansão e aniquilamento das formas de trabalho que ainda sobreviveram à revolução industrial e com avanço da tecnologia perdem terreno fazendo com que massas inteiras a vivam a margem deste processo, sendo descartadas e subproletarizando-se. Neste ciclo parece que estamos assistindo um filme do início de revolução industrial com a volta de epidemias e com milhões de pessoas abaixo da linha de pobreza e as metrópoles ocidentais cada dia mais se estufam de milhões de seres advindos da periferia dos países subdesenvolvidos.

Mais que nunca urge que se adote um modelo de educação que leve em conta este conjunto de fatores que estão cada vez mais empurrando a classe que vive do trabalho para a marginalização. É histórico o descaso das políticas públicas para os que vivem do trabalho na história da educação profissional, pois se privilegiou sempre a formação para as demandas que operadas pelo mercado de trabalho.

Talvez seja o caso de superar a divisão da sociedade em classes para que a educação chegue a classe que mais necessita ter uma educação que equilibre as diferenças e contribua para superar os problemas por ela vividos, já que, ao contrário do que muitos querem fazer crê, não são causados por ela, mas pela sociedade que a dividiu e está pode ser um proposta apresentada em estudos futuros.

\section{Referências}

Franco, M. P. B. (1999). Questões metodológicas e o papel do sujeito pesquisador. In: Trindade, V., Fazenda, I. \& Linhares, C. Os lugares dos sujeitos na pesquisa educacional. Ed. UFMS.

Ferreti, C. J. (2009). O pensamento educacional em Marx e Gramsci e a concepção de politecnia. Trab. educ. saúde. https://www.scielo.br/j/tes/a/GTK9 3QB5JvKdccpjXjyfNyP/?lang=pt.

Junior, J. S. (2007). A educação profissional na ordem regressivo-destrutiva do capital: novos e velhos problemas, velhos e novos desafios, UFPA.

Instituto Federal de Educação, Ciência e Tecnologia Catarinense (2009). Desenvolvimento Institucional - PDI.

Lins, I. (1980). Um novo tempo. https://www.cifraclub.com.br/ivan-lins/novo-tempo/

Maldaner, J. J. (2016). O papel da formação docente na efetividade das políticas públicas de EPT no Brasil - período 2003-2015: implicações políticas e pedagógicas na atuação de professores. UNB, https://repositorio.unb.br/bitstream/10482/20814/1/2016_JairJos\%c3\%a9Maldaner.pdf

Manacorda, M. A. (2007). Aos educadores brasileiros.

Martins, A. L. (2018). A Politecnia como currículo filosófico para o ensino médio integrado. https://www.researchgate.net/profile/Alex-Lara-Martins.

Marx, K. (1983). O capital. Vol. I. Abril Cultural.

Nosella, P. (2011). Ensino médio em busca do princípio pedagógico. Revista Educação e Sociedade.

Pacheco, E. (2011). Novas perspectivas para a rede federal de educação profissional e tecnológica. http://portal.mec.gov.br/setec/arquivos/pdf2 /artigos_novasperspectivas_eliezerb.pdf.

Pasqualli, R., da Silva, V., \& da Silva, A. L. (2019a). Limites e potencialidades de materialização do currículo integrado: uma análise dos planos de ensino e diários de classe. Revista Contexto \& Educação, 34(109), 104-120. https://revistas.unijui.edu.br/index.php/contextoeducacao/article/view/7631. 
Research, Society and Development, v. 10, n. 10, e397101019033, 2021

(CC BY 4.0) | ISSN 2525-3409 | DOI: http://dx.doi.org/10.33448/rsd-v10i10.19033

Pasqualli, R., Silva, A., \& Silva, V. G. da, (20199b). A pesquisa como princípio educativo no currículo integrado. Debates em Educação. 11(24), https://www.seer.ufal.br/index.php/debateseducacao/article/view/6294/pdf.

Rua, M. das. G.. (2014). Análise de Políticas Públicas: Conceitos Básicos. https://educapes.capes.gov.br/bitstream/capes/145407/1/PNAP\%20\%20Modulo\%20Basico\%20-\%20GPM\%20-\%20Politicas\%20Publicas.pdf.

Ortigara, P. \& Ganzeli, C. (2013). Os Institutos Federais de Educação, Ciência Tecnologia - permanência e mudança. In: Batista, E. L \& Muller, T. M. (org.) A educação profissional no Brasil. Ed. Alinea.

Sacristán, J. G. (2013). O que significa o currículo? in Sacristán, J. G. (org). Saberes e incertezas sobre o currículo. Penso.

Santomé, J. T. (1995). O Curriculum Oculto. Porto Editora.

Saviani, D. (2004). A nova lei da educação: trajetória, limites e perspectivas. Autores Associados.

Silva, A. L., Pasqualli. R., Greggio, S., \& Agne, S. A. A. (2016). O Currículo Integrado no Cotiano da Sala de Aula. Publicações do IFSC, https://www.ifsc.edu.br/documents/30701/523474/o_curriculo_integrado.pdf/6151bc15-d409-b17b-1efd-3f21e89314e3.

Silva, V. G. da, \& Pasqualli, R. (2020). A atualidade da pedagogia socialista soviética: um ensaio teórico. Research, Society and Development, 9 (7), https://rsdjournal.org/index.php/rsd/article/view/4388. 